Dr. Dunsheath has wisely concentrated on the heroic age of the second half of the nineteenth century when lighting, traction, telephones and oceanic cables became established, and the attendant problems of generation and insulation were in the main solved. Of 'electron engineering' he tells us less (and nothing of J. L. Baird) owing to the great acceleration and specialization of recent years. But enough is said to point out the moral that the development of electrical theory in respect of thermionic emission and semiconductors was almost wholly the 'result' of technological novelty and not the reverse. The book concludes with chapters on "Professional Organization" and "Social and Historical Background"; a valuable "Chronological Table" and a less-valuable index, from which many useful references to the text are omitted. Documentation and illustration are well chosen.

There are a few typographical slips, of which the repetition of a line of type on p. 93 is the only serious one. "Baronetcy" on p. 215 should be 'Barony'; and readers must be warned that Dr. Dunsheath's reference to Maxwell's famous tribute to Ampère (Treatise, $2,164)$ is not a quotation. W. P. D. WIGHTMAN

\section{PHYSICS FOR STUDENTS OF ELECTRICAL ENGINEERING}

Physics for Electrical Engineers

By Prof. W. P. Jolly. (Physical Science Texts.) Pp. xii + 308. (London: English Universities Press, Ltd., 1961.) 21s. net.

THIS is a very readable little book, published at a modest price, and claiming to cover all the physics required by electrical engineers for the examinations of the Institution of Electrical Engineers and the London B.Sc., and to be of value to students preparing for the graduate examination of the Institute of Physics and for the Higher National Certificate in physics and applied physics.

Students are always grateful for any text-book which gives them exactly the material they need for their examination and nothing more. This book can, therefore, be sure of an appreciative welcome from the harassed student although it may be questioned whether a book which attempts to satisfy the needs of students for so many' different examinations can exactly meet the need of any one of them.

The author divides his work into four sections: on the structure of matter, its electrical properties, radiation of energy and thermodynamics. This is a wide canvas and each succeeding section appears to be more condensed. Thermodynamics is so often taught as a separate engineering subject that it might well have been omitted from this book in order to allow a corresponding expansion of the other three sections. This criticism also applies to some extent to the treatment of electromagnetic waves and of Maxwell's laws, which is very heavily compressed and might better have been omitted, since the subject is usually adequately taught as electrical engineering rather than physics.

Otherwise, the author succeeds in maintaining the interest very well, although forced at times to a somewhat dogmatic treatment in order to avoid introducing mathematics which would be of a too advanced character for his readers.

At the end of each chapter the author gives a number of problems with solutions on the same page
- surely an undesirable practice. The problems are mainly taken from examination papers and are generally disappointing. The numerical questions are usually trifling and do not ensure an adequate understanding of the preceding chapter. The theoretical questions add nothing to the text. The book could be greatly improved by carefully thought out problems designed to clarify and expand the author's treatment of the subject. Examination questions have a different purpose.

The publishers have laid out the text in an attractive fashion, but the number of misprints is rather greater than is usual in a scientific work. Fortunately, few of them are of such a nature as to be likely to mislead the student.

These minor criticisms should not obscure the real merit of the book. It is likely to be useful to graduates as well as to those who still have their examinations ahead of them.

A. H. M. ARNold

\section{POWER SYSTEM ENGINEERING}

\section{Power System Engineering}

An Introduction. By F. do la C. Chard. Pp. xii + 288. (London: Cleaver-Hume Press, Ltd., 1962.) $50 s$.

7 HE rate of increase of the volume of literature dealing with the generation, transmission and distribution of electrical energy remains high. The steady growth of demand for electricity has required increased capacity of generating stations, transmission over longer distances and the interconnexion of larger networks, and has produced new problems and accentuated old ones. To meet these demands new techniques have been devised, and more powerful methods of design and analysis have been developed. These advances are represented in the literature by substantial groups of specialized texts.

Prof. Chard's book lies outside these specialist categories, being a general text of an introductory character. The book aims at giving a general picture of power system performance built up from consideration of the characteristics of the basic components of the system but dealing only, and in as simple a way as possible, with phenomena which are of fundamental importance. The major topics are treated in five chapters.

Chapter 3, entitled "Synchronous Machines, Performance and Control", deals with the basic characteristics of synchronous machines and their behaviour under steady-state and under transient conditions. The next chapter-the transmission line-after a brief treatment of the parameters of three-phase lines and of the equivalent single-phase system, develops the line equations for steady-state transmission and considers the phenomena of reflexion. Thereafter the technique of the power-voltage diagram is developed. Transformers, switch gear and protective gear, constitute the subject of Chapter 5 , while Chapters 6 and 7 deal with the important topics of short circuits and faults together with steady-state and transient system stability. The first two chapters of the book give the underlying circuit theory and set the pattern of treatment. Matrix methods are introduced almost immediately and are utilized throughout the book. The final chapter examines the more important features of extra-high-tension transmission and includes a short section on high-voltage direct-current transmission. 